\title{
Detection of Hamster Squamous Cell Carcinoma Cells (O-1 N) in Blood and Lymph Nodes by Reverse Transcriptase-Polymerase Chain Reaction for Cytokeratin 19
}

\author{
Nobuko Shimizu, Ryozo Kuwano*, Susumu Shingaki, Tamio Nakajima \\ First Department of Oral and Maxill ofacial Surgery, Faculty of Dentistry, Niigata University, 2-5274, Gakkoucho-dori, Niigata City \\ 951-8514, J apan, "Research Laboratory for Molecular Genetics, Niigata University, 1-757, Asahimachi, Niigata City 951-8510, J apan
}

\begin{abstract}
Shimizu N, Kuwano R, Shingaki S and Nakajima T. Detection of hamster squamous cell carcinoma cells (0-1 N) in blood and lymph nodes by reverse transcriptase-polymerase chain reaction for cytokeratin 19. Oral Med Pathol 2000; 5: 71-76, ISSN 1342-0984.

To establish early diagnosis of lymph node metastasis, reverse transcriptase polymerase chain reaction (RT-PCR) for cytokeratin 19 (CK19) mRNA was evaluated in detecting tumor cells in blood and lymph nodes in an animal model of squamous cell carcinoma (termed 0-1 N) with high potential of lymph node metastasis. RT-PCR using primers for CK19 CDNA designed from human counterparts produced a single band of CK19 product which showed high homology with human and mouse CK19 s. CK19 mR NA was expressed in 0-1 N cells, but not of blood and lymph nodes, indicating that CK19 mRNA is a good target of RT-PCR. In a spiking experiment, tumor cells diluted to $10^{2}$ cells $/ 2 \mathrm{ml}$ of blood were detected by RT-PCR. The presence of tumor cells in blood was detected much earlier than the occurrence of lymph node and lung metastases. These results indicate that CK19 mRNA in blood can be used as a predicting marker for lymph node metastasis.
\end{abstract}

Key words: squamous cell carcinoma, metastasis, cytokeratin, reverse transcriptase-polymerase chain reaction

Correspondence: Nobuko Shimizu, First Department of Oral and Maxillofacial Surgery, Faculty of Dentistry, Niigata University, 2-5274, Gakkoucho-dori, Niigata City 951-8514, J apan

Phone 025-227-2881 Fax 025-223-6516

\section{Introduction}

Metastasis is one of the most important biological characteristics of malignant tumors that affect the prognosis of patients. Oral squamous cell carcinomas (SCC) are characterized by local invasiveness and a high rate of metastasis to cervical lymph nodes. The process of metastasis consists of series of multiple tumor-host interactions. To successfully establish a metastasis, tumor cells must leave the primary site, invade the local host tissue, enter the circulation, arrest at the distant vascular bed, extravasate and proliferate at the distant organ site $(1,2)$.

In order to elucidate the mechanism of metastasis of oral carcinomas, we have established an animal model of Iymph node metastasis (termed O-1 $\mathrm{N}$ ) by serial transplantation of a metastatic tumor to the submandibular lymph node from a chemically induced squamous cell carcinoma of the tongue into the buccal pouch in hamsters (3). This model proved to be quite reliable because of the high and constant rate of nodal metastasis and the close resemblance to human oral carcinomas in the process of metastasis (4). Unlike most of the experiments on cancer metastasis in which nude or SCID mice are used, this model is quite unique in that the animals used are not immunodeficient.

Lymph node metastasis is usually determined by histologic examination of a single hematoxylin and eosin stained section, leaving most of the node unexamined. It has been shown in studies of breast cancer that a meticulous analysis with serial sectioning of Iymph nodes resulted in disclosure of micrometastasis in 10-30\% of lymph nodes that had been diagnosed as metastasis free by a routine histologic examination (5). However, such a meticulous study of each node is too time consuming for routine diagnostic pathology.

With the introduction of polymerase chain reaction (PCR) and new tumor markers, the detection of tumor cells in blood or micrometastasis in lymph nodes has become feasible. Mottano et al . (6) reported a highly sensitive detection assay for circulating neuroblasts based on the reverse transcriptase (RT)-PCR amplification of PGP 9.5 mRNA, which is a specific tumor marker for neuroblastoma. Moreno et al . (7) also reported that using RT- 
PCR and prostate-specific antigen mRNA as a tumor marker, they could detect circulating tumor cells in the peripheral blood.

Cytokeratins (CKs), which comprise a multigene family of at least 20 related polypeptides, are constitutents of the intermediate filaments of epithelial cells. They are expressed in various combinations depending on epithelial type and degree of differentiation. For example, cytokeratin 19 (CK 19) is widely distributed and expressed in various epithelia, including normal oral epithelium (8). It has been reported that CK 19 could be a useful marker of occult metastasis to lymph nodes and bone marrow of patients with breast cancer because it is not expressed in lymphoid or hemopoi etic cells $(9,10)$. In the present study, we attempted to detect tumor cells from O-1 N in blood and cervical lymph nodes using CK 19 mRNA RT-PCR. In addition, we compared the sensitivity of conventional histological examination with the CK19 mRNA RT-PCR method in detecting lymph node metastasis.

\section{Materials and Methods}

Cells and cell culture

O-1 N cells were obtained from an animal model of lymph node metastasis established in hamsters (11). 0-1 $\mathrm{N}$ is a squamous cell carcinoma that has been maintained by serial transplantaion of an initial metastatic tumor to the submandibular lymph node from a 9, 10-dimethyl-1, 2-benzanthracene-induced squamous cell carcinoma of the tongue into the buccal pouch in hamsters for over 60 generations. Tumor cells derived from a human oral SCC were used as a positive control. All cells were maintained in IBL Media-I supplemented with $10 \%$ fetal bovine serum (FBS) in a humidified atmosphere with $5 \% \mathrm{CO}_{2}$ in air at $37^{\circ} \mathrm{C}$.

\section{Blood samples}

Blood samples $(2 \mathrm{ml})$ were collected in tubes containing $5 \mathrm{mg}$ ethylene diamine tetraacetic acid (EDTA). Twenty $\mathrm{ml}$ of a hemolytic buffer $\left(10 \mathrm{mM} \mathrm{KHCO}_{3}, 155 \mathrm{mM}\right.$ $\mathrm{NH}_{4} \mathrm{Cl}, 0.1 \mathrm{mM}$ EDTA) were added to the samples. After incubation for $30 \mathrm{~min}$ on ice, the tubes were centrifuged at 3,000 $\times \mathrm{g}$ for $15 \mathrm{~min}$ at room temperature. The pellets were washed with $1 \mathrm{M}$ phosphate-buffered saline ( $\mathrm{pH} 7.4$ ) and were subjected to RNA extraction procedure.

\section{Lymph node samples}

One half of each of lymph node samples was fixed in $4 \%$ paraformaldehide for histological examination. The remaining half was stored at $-80^{\circ} \mathrm{C}$ for the analysis by RT-PCR.

\section{RNA preparation}

Total RNA extraction was performed using ISOGEN (Nippon Gene, Toyama, J apan) for Iymph node samples and ISOGEN LS (Nippon Gene, Toyama, J apan) for blood samples according to the manufacture's instructions. The quantity and quality of the RNA preparations were determined by absorbance at $260 \mathrm{~nm}$ and $280 \mathrm{~nm}$. The RNA preparations were subjected to DNase treatment before RT-PCR analysis to eliminate genomic DNA contamination.

\section{Reversetranscriptase polymerasechain reaction}

Two $\mu \mathrm{g}$ of total RNA was reverse transcribed by Molony Murine Leukemia Virus Reverse Transcriptase (Gibco) at $42^{\circ} \mathrm{C}$ for 60 min using a random primer (Gibco) in $20 \mu \mathrm{l}$ of the reaction mixture. Reactions in which the RNA template was replaced by water were used as RTnegative controls. Synthesized cDNA was stored at $-20^{\circ} \mathrm{C}$. One $\mu$ l of the products was subjected to the PCR amplification.

PCR was carried out under the following conditions; $93^{\circ} \mathrm{C}$ for $1 \mathrm{~min}, 60^{\circ} \mathrm{C}$ for $1 \mathrm{~min}$, and $72^{\circ} \mathrm{C} 2 \mathrm{~min}$ for $30 \mathrm{cycle}$, in a $10 \mu \mathrm{l}$ solution of $10 \mathrm{mM}$ Tris- $\mathrm{HCl}(\mathrm{pH}$ 8.3), $50 \mathrm{mM}$ $\mathrm{KCl}, 1.5 \mathrm{mM} \mathrm{MgCl}, 2.5 \mathrm{mM}$ dNTPs, $10 \mu \mathrm{M}$ of each of the primers and $0.4 \mathrm{u}$ of Taq polymerase (Takara). RT-PCR products were analyzed by $1.5 \%$ agarose gel electrophoresis and ethidium bromide staining. PCR primer sequences used are given in Table 1 . The PCR primers for CK 19 and GAPDH were designed from the human counterparts because their sequences for the hamster are not reported.

\section{Sequencing of PCR products}

To verify the PCR product obtained with the cytokeratin 19 primers, it was cloned into PCR 2.1 Vector (I nvitrogen). The purified plasmid DNA was sequenced by the dideoxy-mediated chain-termination method.

\section{Cell spiking experiment}

Cell spiking experiments were used to test the potential sensitivity of the technique for detection of 0-1 N cells in the blood. O-1 N cells (10-10 $)$ were added to $2 \mathrm{ml}$ of whole blood samples from a healthy hamster, total RNA was extracted from the cell-spiked blood samples and RT-PCR for CK 19 mRNA was performed.

Table 1: Primer sequences used for amplification of CK 19 and GAPDH

\begin{tabular}{lll}
\hline mRNA & & Primers 5'-3' \\
\hline CK19 & Sense primer & GCGGGACAAGATTCTTGGTG \\
& Antisense primer & CTTCAGGCCTTCGATCTGCAT \\
GAPDH & Sense primer & GAAATCCCATCACCATCTTCCAGG \\
& Antisense primer & CATGTGGGCCATGAGGTCCACCAC \\
\hline
\end{tabular}


Experimental system of lymph nodeand lung metastasis

Twenty eight Syrian golden hamsters, 4 weeks of age, were used in the experiment. Metastatic tumors of submandibular lymph nodes of O-1 N were removed from donor hamsters and minced into small pieces of approximately $2 \mathrm{~mm}^{3}$ in size under aseptic conditions. A piece of tumor tissue was transplanted into the buccal pouch of recipient hamsters. Four hamsters with successful takes were killed every 2 weeks from 2 to 10 weeks and every 4 weeks from 14 to 18 weeks after transplantation under ether anesthesia to examine the growth of buccal pouch tumors, lymph node metastasis and lung metastasis. Blood was obtained directly from the heart by thoracotomy to avoid contamination of skin fragments. The submandibular lymph nodes and lungs were dissected out via a submandibular skin incision.

\section{Histologic examination}

The specimens were fixed with $4 \%$ paraformaldehyde, embedded in parafin, sectioned at $4 \mu \mathrm{m}$ and stained with hematoxylin-eosin (H-E).

\section{Results}

RT-PCR detection of O-1 N cells

The expected molecular sizes of amplified CK 19 PCR products were $214 \mathrm{bp}$. The PCR product for CK 19 of O-1 $\mathrm{N}$ cells showed a single band on etidium bromide stained-gels, corresponding to the 214 bp of the human oral squamous cell line used as a positve control (Fig. 1).

\section{Sequence of CK 19 PCR product}

The sequence of amplified CK 19 from O-1 N by PCR are shown in Table 2. The sequence of PCR product showed homology of $92.1 \%$ and $91.1 \%$ to those of the mouse and human CK $19 \mathrm{~s}$, respectively.

\section{Blood and lymph nodeanalysis}

In 5 blood and 5 lymph node samples obtained from healthy hamsters as controls, CK 19 RT-PCR products were undetectable by ethidium bromide staining except for the positive control. RNA integrity was confirmed in

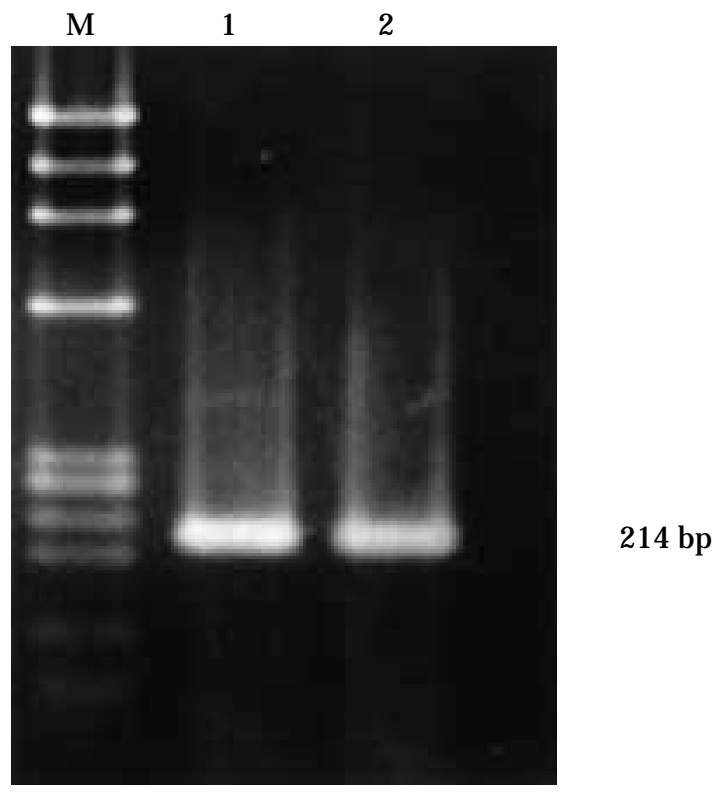

Fig. 1: Products of RT-PCR for CK 19 mRNA separated by agarose gel electrophoresis and stained with ethidium bromide in 0-1 $\mathrm{N}$ cells and human oral SCC cells. M: size markers. Lane 1: 0-1 N cells. Lane 2: human oral SCC cells used as positive control.

all samples by the detection of 782 bp GAPDH product in ethidium bromide-staining gels constantly (Fig. 2a and b).

Sensitivity for detection of tumor cells

In order to test the sesitivity for detection of O-1 N cells in the peripheral blood, a cell spiking experiment was performed. No bands were demonstrated at a concentration of 10 tumor cells added to $2 \mathrm{ml}$ of whole hamster blood. A faint band was seen at a concentration of $10^{2}$ tumor cells $/ 2 \mathrm{ml}$ of blood, and a much clearer band was seen at a concentration of $10^{3}$ tumor cells $/ 2 \mathrm{ml}$ of blood. Thus, more than $10^{2} \mathrm{O}-1 \mathrm{~N}$ cells $/ 2 \mathrm{ml}$ of blood were needed to detect the presence of the cells (Fig. 3).

\section{Detection of CK19 in circulating blood}

At 2 weeks after transplantaion of 0-1 N, blood

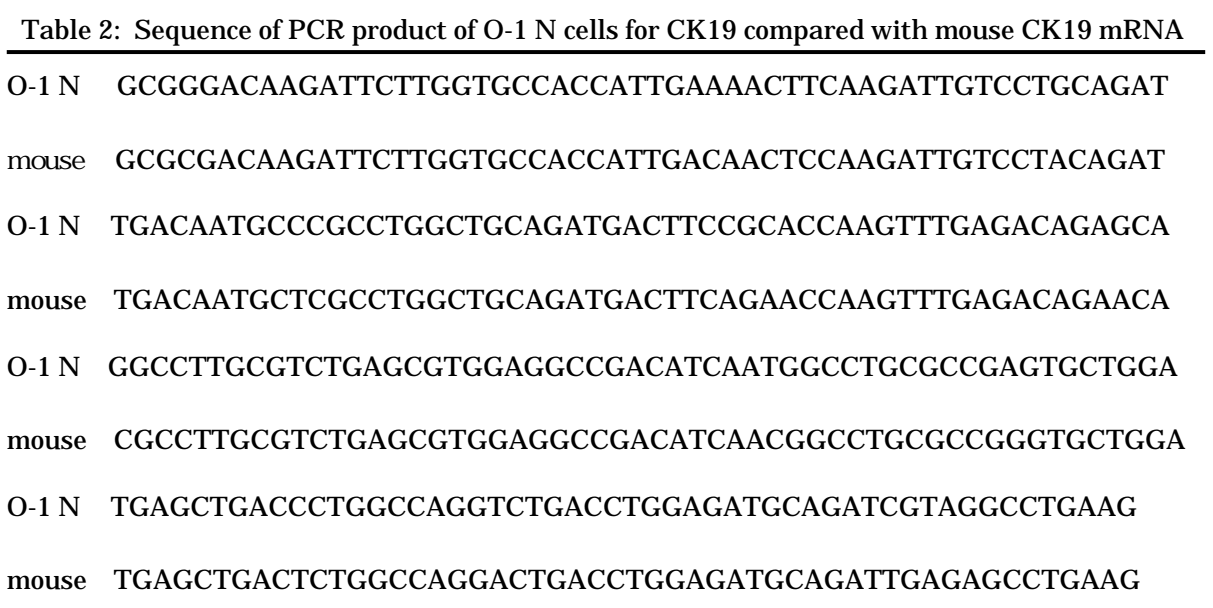


samples showed no band of the CK19 RT-PCR product. However, at 4 to 18 weeks CK 19 mRNA was detected in all blood samples by RT-PCR (Table 3 ).

Comparison in detecting lymph node metastasis between histological examination and CK19RT-PCR

The results of histological examination were compared with those of CK19 RT-PCR in detecting of mi-
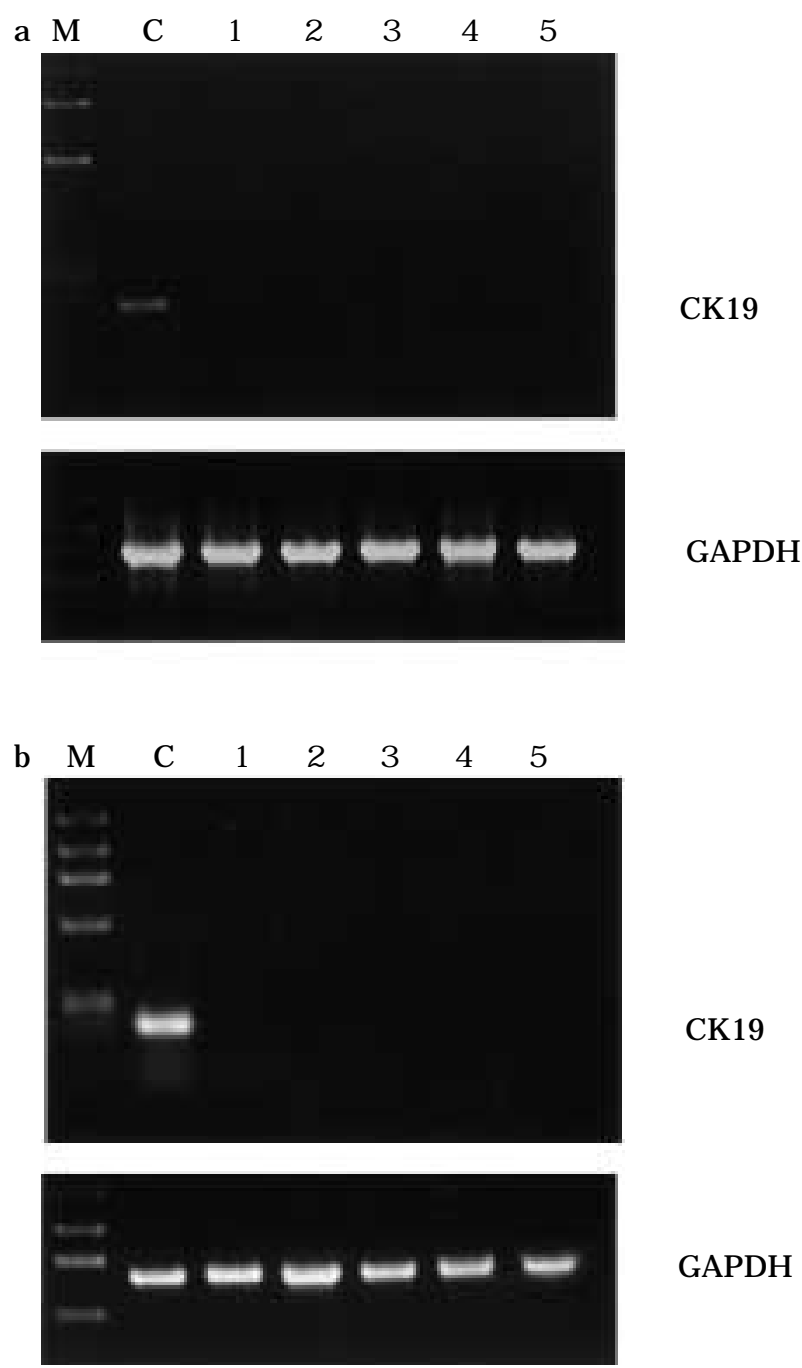

Fig. 2: RT-PCR amplification of CK19 mRNA and GAPDH mRNA from normal blood (a) and normal lymph nodes (b). CK 19 RT-PCR products are negative in normal blood and lymph nodes except for the positive control. M: size markers. C: positive control of O-1 N cells. Lane 1-5: hamster samples. crometastasis in 28 lymph nodes (Table 3).

Two and four weeks after transplantation no bands were seen in all 8 lymph nodes. Histologically, they were also negative. One of 4 lymph nodes at 6 weeks was positive in both CK 19 RT-PCR and histological examination. At 8 weeks, CK 19 product was detected in 2 of 4 lymph nodes. These nodes were found to have metastasis in histological examination. After 10 weeks, lymph node metastasis was confirmed in all samples in both CK 19 RT$P C R$ and $H-E$ staining. Thus, there was no difference in detecting metastasis between the RT-PCR analysis and histological examination.

\section{Lung metastasis}

At 2 to 10 weeks, lung metastasis was not confirmed histologically in any animals. At 14 and 18 weeks, it was detected in one and 3 animals, with lymph node metastasis, respectively.

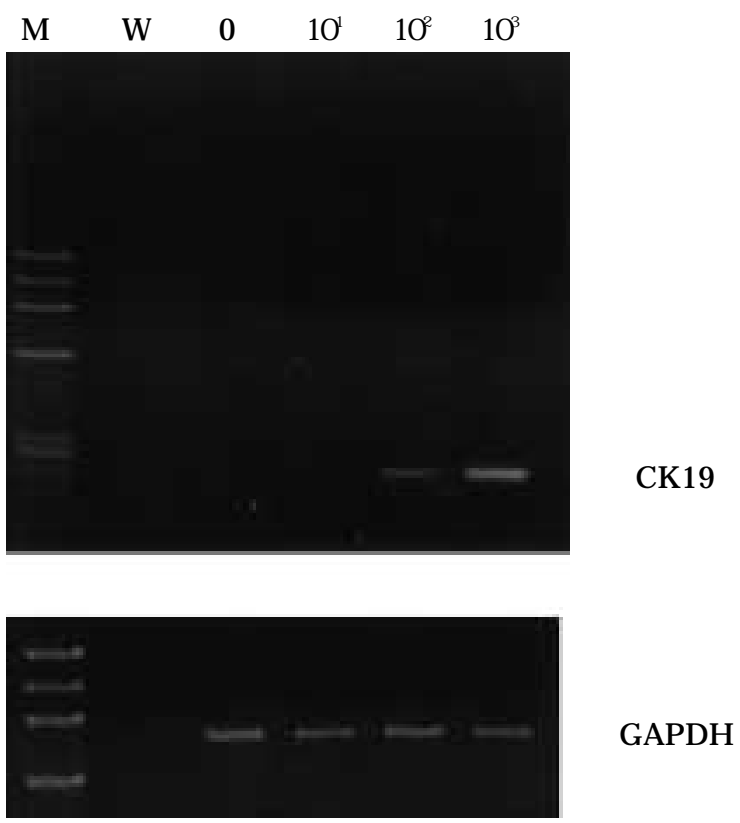

Fig. 3: RT-PCR amplification of CK 19 mRNA from blood samples spiked with O-1 N cells. CK 19 bands are seen at concentrations exceeding $10^{2}$ tumor cells in $2 \mathrm{ml}$ of whole blood. $\mathrm{M}$ : size markers. W: water negative control.

Table 3: Comparison between histological examination and CK 19 RT-PCR for detection of micrometastasis in lymph nodes

\begin{tabular}{|c|c|c|c|c|c|c|c|c|}
\hline \multicolumn{6}{|c|}{ Time in weeks } & \multirow[b]{2}{*}{$10 w$} & \multirow[b]{2}{*}{$14 w$} & \multirow[b]{2}{*}{$18 w$} \\
\hline & & $2 w$ & $4 w$ & $6 w$ & $8 w$ & & & \\
\hline blood & $\begin{array}{l}\text { RT-PCR } \\
\text { positive }\end{array}$ & $0 / 4$ & $4 / 4$ & $4 / 4$ & $4 / 4$ & $4 / 4$ & $4 / 4$ & $4 / 4$ \\
\hline \multicolumn{2}{|c|}{$\begin{array}{l}\text { RT-PCR } \\
\text { positive nodes }\end{array}$} & $0 / 4$ & $0 / 4$ & $1 / 4$ & $2 / 4$ & $4 / 4$ & $4 / 4$ & $4 / 4$ \\
\hline \multicolumn{2}{|c|}{$\begin{array}{l}\text { Histologically } \\
\text { positive nodes }\end{array}$} & $0 / 4$ & $0 / 4$ & $1 / 4$ & $2 / 4$ & $4 / 4$ & $4 / 4$ & $4 / 4$ \\
\hline
\end{tabular}




\section{Discussion}

The expression of CKs by epithelial tissues and their expression following malignant transformation have made them reliable markers in diagnostic surgical pathology. We studied the possible use of CK 19 as a target for RT-PCR detection of metastasizing tumor cells of O-1 $N$, squamous cell carcinoma with high potential of lymph node metastasis in hamsters.

CK 19 is expressed predominantly in the basal cells of noncornified epithelia. CK19 mRNA and protein are also detectable in oral SCCs (12). In this study, RT-PCR of CK 19 resulted in producing a clear single band of 214 $\mathrm{bp}$. The sequence of PCR product of O-1 N amplified with the CK 19 primers showed high homology with the sequences of mouse and human CK19 s. Thus, it proved to be a sensitive and specific method for detecting 0-1 N cells in blood and lymph nodes in hamsters.

According to Krismann et al . (13), the specificity of detecting malignant cells using RT-PCR for CK 19 was low because false positive reactions were observed in peripheral blood cells in a significant number of healthy subjects $(13,14)$. Gunn et al . (14) also reported that CK 19 gene expression was detected in lymph nodes and bone marrow aspirates from control subjects. They, therefore, concluded that CK19 RT-PCR is of no value as a marker of occult lymph node and bone marrow metastasis. The false positive results are thought to be DNA (15) or amplification of CK 19 transcripts from contaminating epithelial cells. In our study, utmost care was taken to prevent the contamination of normal epithelial cells by taking blood directly from the heart after thoracotomy and Iymph nodes via a submandibular incision. In a preliminary experiment, CK 19 gene expression was not detected in any blood sample, but false positivity was seen in $40 \%$ of normal Iymph nodes. Therefore, DNase was treated before cDNA synthesis to eliminate the effects of pseudogene contamination. Then, the CK 19 band became undetectable in control lymph node samples as well.

In the sensitivity study of this method, at least $10^{2}$ O-1 $\mathrm{N}$ cells in $2 \mathrm{ml}$ whole blood were needed to detect their presence. The sensitivity is comparable to that reported in other study (16).

The presence of O-1 N cells was detected by CK 19 RT-PCR in all 4 blood samples 4 weeks after transplantation of O-1 N. At this stage, O-1 N started to show diffuse invasion of surrounding tissues with induction of a stroma rich in blood and lymphatic vessels. However, direct invasion of these vessels by $\mathrm{O}-1 \mathrm{~N}$ was not always confirmed in histologic examination of the transplanted buccal tumors. Lymph node metastasis was also observed in no animals at 4 weeks, whereas it occurred in all animals at 10 weeks. Therefore, detection of tumor cells in blood could be a sign in predicting lymph node metastasis. Lymph node metastasis was also correlated to the presence of Iymph vascular invasion by tumor cells in human specimens (17). In O-1 N, lung metastasis occurred only in animals with lymph node metastasis. The presence of tumor cells was confirmed in blood by CK19 RT-PCR from 4 weeks to 18 weeks when lung metastasis developed in all animals. Therefore, it may be interesting to study the relationship between tumor cell concentration in blood and occurrence of lung metastasis.

Noguchi et al . (18) have reported that $15 \%$ of normal lymph nodes were CK 19 RT-PCR positive in gastric cancer. McDonald et al . (19) also showed that $40 \%$ of histologically negative Iymph nodes were found to be positive by CK 5 RT-PCR in head and neck cancer. According to Shingaki et al . (20), however, serial sectioning revealed occult metastasis in only two $(0.3 \%)$ of the 716 lymph nodes which were negative in routine histological examination of one section in patients with head and neck carcinoma. The rate of missed metastasis was as low as 5\% in breast cancer in an analysis of histologically negative lymph node by CK 19 RT-PCR (21). There were no lymph nodes with metastatic involvement which were false negative to CK 19 RT-PCR in our study. There were also no CK19 RT-PCR positive nodes which were histologically metastasis-negative. Because there was no difference in the sensitivity and timing in detecting lymph node metastasis between CK19 RT-PCR and histological examination, CK 19 RT-PCR would be of no significant value for the purpose.

In conclusion, CK19 RT-PCR of blood samples is of value in predicting lymph node metastasis, but it does not contribute significantly in detecting lymph node metastasis.

\section{Acknowledgments}

We wish to thank Dr. Kimimitsu Oda (Department of Oral Biochemistry) for helpful suggestions and Dr. Hitoshi Kawamata ( Second Department of Oral and MaxilIofacial Surgery, Tokushima University) for technical support.

\section{References}

1. Liotta LA, Steeg SP and Stetler-Stevenson GW. Cancer metastasis and angiogenesis: An imbalance of positive and negative regulation. Cell 1991; 64: 327-36.

2. Liotta LA and Stetler-Stevenson GW. Tumor invasion and metastasis: An imbalance of positive and negative regulation. Cancer Res 1991; 51: Suppl. 5054s-9s.

3. OhtakeK, Shingaki S and Nakajima T. A model for the study of lymph node metastasis from oral carcinoma by serial transplantation of metastatic tumor in hamsters. Oral Surg Oral Med Oral Pathol 1990; 69: 701-7.

4. Ohtake K, Shingaki S and Nakajima T. Histologic study on the metastatic process in the experimental model of lymph node metastasis. Oral Maxillofac Pathol 1993; 75: 472-78.

5. International (Ludwig) breast cancer study group. Prognostic importance of occult axillary lymph node micrometastases from breast cancers. Lancet 1990; 335: 1565-8.

6. Mattano LA, Moss TJ and Emerson SG. Sensitive detection of rare circulating of rare circulating neuroblastoma cells by the reverse transcriptase-polymerase chain reaction. Cancer 
Res 1992; 52: 4701-5.

7. Moreno J G, Croce CM, Fiscer R, et al . Detection of hematogenous micrometastasis in patients with prostate cancer. Cancer Res 1992; 52: 6110-2.

8. Moll R, Franke WW, Schiller DL, et al . The catalog of human cytokeratins: patterns of expression in normal epithelia, tumor and cultured cells. Cell 1982; 31: 11-24.

9. Traweek ST, Liu J and Battifora H. Keratin gene expression in non-epithelial tissues. AmJ Pathol 1993; 142: 1111-8.

10. Noguchi S, Aihara T, Motomura K, et al . Histologic characteristics of breast cancers with occult lymph node metastases detected by keratin 19 mRNA reverse transcriptase-polymerase chain reaction. Cancer 1996; 78: 1235-40.

11. Takada M, Fukuda T and Nakajima T. Establishment of a cell line derived from squamous cell carcinoma with a high metastatic potency to regional lymph nodes. Asian J Oral Maxillofac Surg 1994; 6: 91-6.

12. Su L, Morgan PR and Lane EB. Keratin 14 and 19 expression in normal, dysplastic and malignant oral epithelia. A study using in situ hybridization and immunohistochemistry. J Oral Pathol Med 1996; 25: 293-301.

13. Krismann M, Todt B, Schröer J, et al . Low specificity of cytokeratin 19 reverse transcriptase-polymerase chain reaction analyses for detection of hematogenous lung cancer dissemination.J Clin Oncol 1995; 13: 2769-75.

14. Gunn J , McCall J L, Y un K, et al . Detection of micrometastases in colorectal cancer patients by K 19 and K 20 reversetranscription polymerase chain reaction. Lab Invest 1996; 75: 611-6.

15. Ruud P, Fodstad $\Phi$ and Hovig E. I dentification of a novel cy- tokeratin 19 pseudogene that may interfere with reverse transcriptase-polymerase chain reaction assays used to detect micrometastatic tumor cells. Int J Cancer 1999; 80: 11925.

16. Burchill SA, Bradbury MF, Pittmsn K, et al . Detection of epithelial cancer cells in peripheral blood by reverse transcriptase-polymerase chain reaction. Br J Cancer 1995; 71: 27881.

17. Shingaki S, Suzuki I, Nakajima T, et al . Evaluation of histopathologic parameters in predicting cervical lymph node metastasis of oral and oropharyngeal carcinomas. Oral Surg Oral Med Oral Pathol 1988; 66: 683-8.

18. Noguchi S, Hiratsuka M, Furukawa $\mathrm{H}$, et al . Detection of gastric cancer micrometastases in lymph nodes by amplification of keratin 19 mRNA with reverse transcriptase-polymerase chain reaction. J pn J Cancer Res 1996; 87: 650-4.

19. McDonald LA, Walker DM and Gibbins J R. Cervical lymph node involvement in head and neck cancer detectable as expression of a spliced transcript of typell keratin K 5 . Oral Oncol Eur J Cancer 1998; 34: 276-83.

20. Shingaki S, Ohtake $K$, Nomura $T$, et al. The value of single versus multiple sections for detection of lymph node metastasis. J Oral Maxill ofac Surg 1991; 49: 461-3.

21. Lockett MA, Metcalf J S, Baron PL, et al . Efficacy of reverse transcriptase-polymerase chain reaction screening for micrometastic disease in axillary lymph nodes of breast cancer patients. Am Surg 1998; 64: 539-44.

(Accepted for publication August 28, 2000) 